\title{
Modal Analysis of the Frame Structure of a Hybrid Electric City Bus
}

\author{
Kan Hu ${ }^{\text {a }}$, Zuoqiang Dai ${ }^{b}$, Tiezhu Zhang ${ }^{\mathrm{c}}$ \\ School of Qingdao University, Qingdao 266071, China \\ a694937470@qq.com, bdaizuoqiangqdu@163.com, ‘qdzhangtz@163.com
}

\begin{abstract}
The vibration problem of the vehicle in the running process due to excitation by various external loads and the transmission part of the resulting, in this paper, based on the theory of modal analysis, the natural frequencies and natural modes of a hybrid electric city bus frame are solved. The result is compared with the external disturbance frequency is shown that the resonance phenomenon will not occur during the normal running of the vehicle. This study provides a theoretical basis for the structural design and optimization of the frame.
\end{abstract}

Keywords: Frame; Finite element; Modal analysis; Resonance.

\section{Introduction}

Vehicles in the process of driving, if the excitation frequency is close to the natural mode frequency of the frame, it will cause resonance. Resonance phenomenon will not only affect the ride comfort and ride comfort of the Vehicle, but also cause the destruction of the frame structure.Therefore, we need to analyze the natural frequency of the frame $[1,2]$.The natural frequency of the frame structure can be obtained by the modal analysis of the frame, which provides theoretical basis for the improvement of the frame structure.

\section{The establishment of finite element model}

The frame structure of total length, width and height is $9950 \mathrm{~mm}, 850 \mathrm{~mm}$ and $632 \mathrm{~mm}$, the channel thickness is $8 \mathrm{~mm}$. Frame structure material is Q345, its Young's modulus of elasticity is, Poisson ratio is 0.28 , density isand Yield limit is $345 \mathrm{MPa}$.

Follow the following principles when establishing finite element models:In order to save the time of processing and calculating, the decorative component and the non load bearing element which are not affected by the actual force of the frame are neglected.Ignoring the impact of the overall strength of the frame is small, but the overall quality of the mesh has a great impact on the smaller diameter of the bolt hole, riveting hole and excessive fillet[3].In order to improve the accuracy of calculation, the stress concentration of the components in the frame structure can be reduced, and the number of the grid is increased.The finite element model of the frame after dividing mesh is shown in Figure 1.

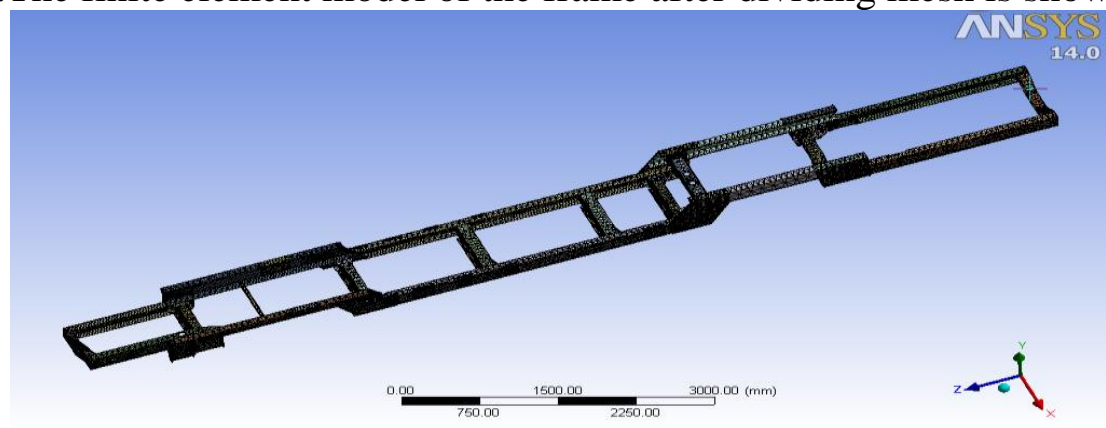

Figure 1 The finite element model of the frame

\section{Modal analysis of frame}

For large engineering structures, the low order vibration has a great influence on the dynamic structure, so it only needs to calculate the natural frequencies and modes of the first few orders [4].In this paper, combined with the actual structure of the frame and the load, the analysis and calculation of the frame structure of the first 6 modes. The vibration mode of the first 6 modes is shown in Figure 
2 Figure 7.The natural frequency, vibration mode and maximum deformation of the frame are shown in Table 1.

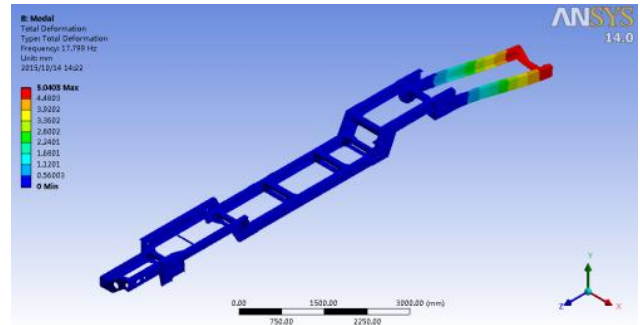

Fig. 2 The first mode

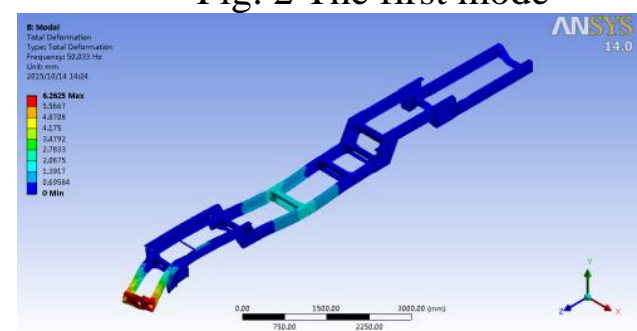

Fig.4 The third mode

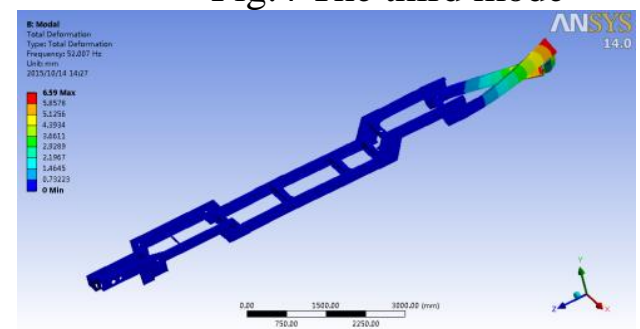

Fig.6 The fifth mode

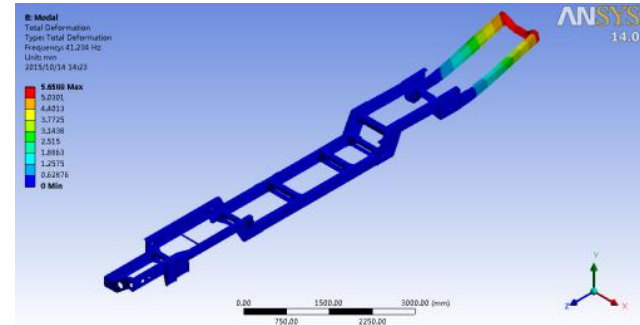

Fig.3 The second mode

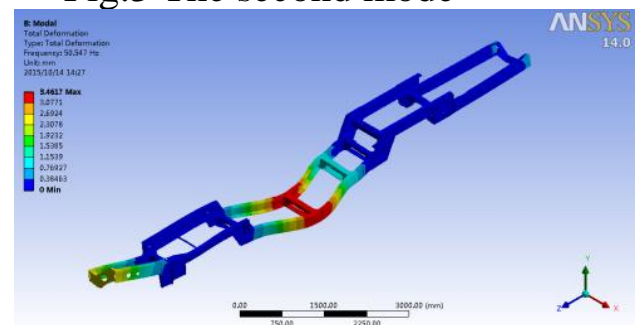

Fig.5 The fourth mode

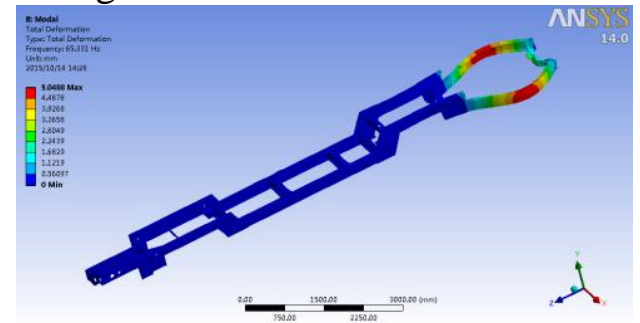

Fig.7 The sixth mode

Table1 Modal analysis results of frame

\begin{tabular}{cccc}
\hline Order number & $\begin{array}{c}\text { Natural frequency } \\
/ \mathrm{Hz}\end{array}$ & Modal characteristics & $\begin{array}{c}\text { Maximum } \\
\text { deformation } / \mathrm{mm}\end{array}$ \\
\hline 1 & 17.799 & $\begin{array}{c}\text { Swing around the Y axis of the rear section of } \\
\text { the vehicle frame } \\
\text { Bending of the rear section of the frame } \\
\text { around the X axis }\end{array}$ & 5.0403 \\
3 & 41.234 & $\begin{array}{c}\text { Swing around the Y axis of the front section of } \\
\text { the vehicle frame }\end{array}$ & 6.6588 \\
4 & 50.033 & $\begin{array}{c}\text { Swing around the Y axis of the middle of the } \\
\text { vehicle frame }\end{array}$ & 3.4617 \\
5 & 50.547 & $\begin{array}{c}\text { Torsion of the rear section of the frame around } \\
\text { the Z axis }\end{array}$ & 6.5900 \\
6 & 52.007 & After the longitudinal outward swing frame & 5.0488 \\
\hline
\end{tabular}

\section{Result analysis}

In the course of driving, the frame is working under the action of dynamic load, so the frame should meet the following principles in the design process:The natural frequency of the frame should avoid the vibration induced by the road roughness. When the passenger car is running, the random excitation of road surface roughness on the wheel can cause the wheel unbalance in about $20 \mathrm{~Hz}$; The first mode of the frame should avoid the idle speed of the engine. The idle speed of engine vibration frequency is determined by the idle speed of the engine, the number of cylinders and the number of strokes, calculating formula for $f=\frac{2 n z}{60 \tau}[5,6]$. In the formula, $\mathrm{n}$ is the engine speed, $\mathrm{z}$ is the engine cylinder number and $\tau$ is the engine stroke number.

In this paper, the analysis of the use of passenger car engine type for the inline four cylinder six stroke water cooled engine, idle speed is $600 \mathrm{r} / \mathrm{min}$, by the formula calculation of idle vibration 
frequency of $30 \mathrm{~Hz}$.From Table 1 data shows that the 1 modal frequency of the bus is $17.799 \mathrm{~Hz}, \mathrm{o}$ avoid the road in the face of the excitation frequency of passenger cars, but also lower than the speed of the engine idle running frequency, to meet the design requirements.

\section{Summary}

In this paper, through the modal analysis of the frame structure, shows the frame of each order natural frequency can reasonable avoid caused by road roughness excitation frequency and engine idle speed, so that the frame resonance does not occur.By means of the modal analysis method, it can be used to test whether the frame is reasonable in the design process, to avoid the resonance phenomenon caused by the vehicle in the course of driving, and the damage of the components and the safety problem.

\section{Acknowledgements}

This work was financially supported by the National Science-technology Support Plan Projects "The key technology and application of lithium ion power battery based on the new high safety diaphragm" under Grant No. 2012 BAG 26 B 02.

\section{References}

[1]. Lei Feng, Shiyong Guo, Bin Xu and so on. Analysis on dynamic characteristics of bus frame based on MSC. Nastran [J]. Bus technology and research, 2009, 33 (3): 10-11, 16.

[2]. Yong Hua, Shangping Li, Bing Li and so on. Modal experiment and verification of low speed truck frame [J]. Agricultural equipment and vehicle engineering, 2013, 51 (1): 5-8.

[3]. Dawei Liu, Tianyi Yan, Zhenguo Dong and so on. Modal analysis of semi-trailer frame [J]. Information of manufacturing industry in China, 2006, 35 (11): 57-59, 63.

[4]. Yonghua Xiong, Farong $\mathrm{Du}$, Feng Gao and so on. Analysis and Research on dynamic characteristics of light truck frame [J].Machine design, 2007, 24 (4): 60-62.

[5]. Yong Wang, Bei Sun, Yun Li and so on. Dynamic characteristics analysis of a heavy truck frame [J]. achinery and electronics, 2013, (4): 70-72.

[6]. Yu Ma, Yongying Chang, Yuwen Li and so on. Modal analysis and transient response analysis of bus frame [J].Journal of Zhengzhou University of Light Industry (Natural Science Edition), 2006, 21 (3): 58-60. 